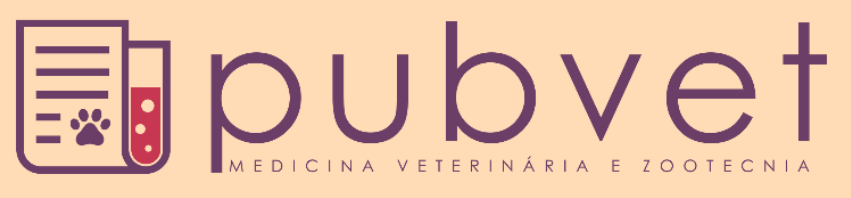

https://doi.org/10.31533/pubvet.v14n8a630.1-6

\title{
Primeiro relato da ocorrência de Hepatozoon spp. no município de Santa Teresa, Espírito Santos
}

\author{
Paula de Oliveira Braga ${ }^{1} \bullet$, Patrícia Gonçalves Zanetti ${ }^{2}$, Valéria Bobbio Resende ${ }^{3}{ }^{\bullet}$, Elisa \\ Bourguignon Dias da Silva $^{4}{ }^{\circ}$, Rômulo Silva de Oliveira $^{5}{ }^{\circ}$, Rogério Magno do Vale Barroso ${ }^{6 *} \bullet$ \\ ${ }^{I}$ Professora especialista da Universidade Vale do Rio Doce (UNIVALE), Curso de Medicina Veterinária. Governador Valadares-MG Brasil. \\ ${ }^{2}$ Médica Veterinária autônoma. Vitória-ES, Brasil \\ ${ }^{3}$ Médica Veterinária autônoma. Sooretama-ES, Brasil. \\ ${ }^{4}$ Médica Veterinária Mundo Zen Petshop. Santa Teresa-ES, Brasil. \\ ${ }^{5}$ Médico Veterinário da Universidade Federal do Acre - Unidade de Ensino e Pesquisa em Medicina Veterinária. \\ ${ }^{6}$ Professor Adjunto da Universidade Federal do Acre, Departamento de Ciências Biológicas e da Natureza (CCBN). Rio Branco/AC Brasil. \\ *Autor para correspondência, E-mail: vetbarroso@yahoo.com.br
}

\begin{abstract}
Resumo A hepatozoonose é uma doença causada por protozoários, pertencentes ao gênero Hepatozoon. No Brasil, Hepatozoon canis foi relatado como causador da doença em cães. A transmissão se dá após a ingestão de carrapatos infectados, sendo que, a musculatura e os leucócitos são os locais de parasitismo. Tremores musculares, mialgia e hipertermia são sinais clínicos que podem ocorrer em cães afetados. O diagnóstico pode ser realizado pela detecção das formas gamontes em leucócitos no esfregaço sanguíneo, e para tratamento o dipropionato de imidocarb é a droga de escolha. Objetivou-se com este trabalho descrever o primeiro caso de hepatozoonose canina, no município de Santa Teresa-ES, utilizando-se o histórico de atendimento do animal afetado. O presente estudo alerta para um possível sub-diagnóstico da doença por provável desconhecimento dos médicos veterinários e revê a literatura acerca deste parasita ainda pouco conhecido.
\end{abstract}

Palavras chave: cão, diprionato de imidocarb, hemoparasitose, hepatozoonose

\section{First case report occurrence of Hepatozoon spp. in the municipality of Santa Teresa, Espirito Santos}

\begin{abstract}
Hepatozoonosis is a disease caused by a protozoan of Hepatozoon genus. In Brazil, Hepatozoon canis has been reported to cause disease in dogs. Transmission occurs after ingestion of infected ticks, and the muscles and leukocytes are parasitism locations. Muscle tremors, myalgia and clinical hyperthermia are signals that can occur in affected dogs. Diagnosis can be accomplished by the detection of gamonts forms inside leukocytes from blood smears and for the treatment, imidocarb dipropionate is the drug of choice. The objective of this work is to describe the first case of canine hepatozoonosis in the municipality of Santa Teresa-ES, using the medical records of the infected animal. This study highlights the possibility of underdiagnosis of the disease, probably due to the lack of veterinarian's knowledge about it and it also reviews the literature about this little-known parasite.
\end{abstract}

Keywords: dog, imidocarb diprionate, hemoparasitosis, hepatozoonosis

\section{Primer informe de la aparición de Hepatozoon spp. en el municipio de Santa Teresa, Espírito Santos}

Resumen. La hepatozoonosis es una enfermedad causada por protozoos, perteneciente al género Hepatozoon. En Brasil, se ha informado que Hepatozoon canis causa la enfermedad en 
perros. La transmisión ocurre después de comer garrapatas infectadas, los músculos y los leucocitos son los sitios de parasitismo. Los temblores musculares, la mialgia y la hipertermia son signos clínicos que pueden ocurrir en los perros afectados. El diagnóstico se puede hacer mediante la detección de gamontes en leucocitos en el frotis de sangre, y para el tratamiento, el dipropionato de imidocarb es el fármaco de elección. El objetivo de este trabajo fue describir el primer caso de hepatozoonosis canina, en el municipio de Santa Teresa-ES, utilizando la historia de cuidado del animal afectado. El presente estudio advierte de un posible diagnóstico insuficiente de la enfermedad debido a la falta de conocimiento de los veterinarios y revisa la literatura sobre este parásito, que aún es poco conocido.

Palabras clave: perro, diprionato de imidocarb, hemoparasitosis, hepatozoonosis

\section{Introdução}

A hepatozoonose canina é uma hemoparasitose causada por protozoários do gênero Hepatozoon spp. pertencentes ao filo Apicomplexa, família Hepatozoidae e subordem Adeleorina (Baneth, 2006; Greene et al., 1993; Hartmann, 2006)

O primeiro relato da infecção foi na Índia em células polimorfonucleares de cães residentes na zona rural (Bentley, 1905). No Brasil constam relatos nos estados de São Paulo (O’Dwyer et al., 2004), Rio de Janeiro (Massard, 1979; O’Dwyer et al., 2001), Espírito Santo (Massard, 1979; Spolidorio et al., 2009), Mato Grosso do Sul (Ramos et al., 2015) e Distrito Federal (Paludo et al., 2003).

A transmissão se dá pela ingestão do carrapato Rhipicephalus sanguineus infectado (Greene et al., 1993). No entanto, existem relatos de outras espécies de carrapatos no Brasil que podem estar relacionadas à infecção, como o gênero Amblyomma (Massard, 1979).

$\mathrm{O}$ aparecimento dos sinais clínicos ocorre por volta de quatro semanas após a ingestão do hospedeiro intermediário, podendo se agravar ou até mesmo regredir de acordo com a liberação dos protozoários na musculatura, aumentando a miosite, dor muscular e a febre, levando a quadros de mialgia, rigidez muscular, claudicação, perda de peso progressiva, fraqueza, atrofia muscular, secreção ocular mucopurulenta e diarreia sanguinolenta passageira (Birchard \& Sherding, 2008; Mundim et al., 2002).

A técnica de esfregaço sanguíneo é a mais empregada no diagnóstico de rotina, sendo o mesmo confirmado pela identificação dos gametócitos no interior dos leucócitos infectados. Já suas formas merontes são encontradas através de citologia e histologia por biópsia de órgãos hemolinfáticos (Gonen et al., 2004).

Pretende-se, com o presente trabalho, descrever o primeiro relato de caso de hepatozoonose em um cão no município de Santa Teresa, Espírito Santo, por ser uma doença pouco conhecida entre os médicos veterinários e por apresentar sintomatologia similar a outras hemoparasitoses.

\section{Relato de caso clínico}

Uma cadela da raça Labrador, de aproximadamente 6 anos, não castrada, pesando $40 \mathrm{~kg}$, domiciliado na Zona Rural do município de Santa Teresa-ES, foi atendido na Clínica Escola Veterinária Dr. Laurindo Costa Neto, da Escola de Ensino Superior São Francisco de Assis.

$\mathrm{Na}$ anamnese, o proprietário relatava que o animal apresentava apetite seletivo e apatia sendo observado a presença de carrapatos. Durante o exame físico foi constatada dor abdominal e esplenomegalia, demais parâmetros estavam dentro da normalidade.

$\mathrm{O}$ resultado do hemograma do paciente apresentou linfopenia: 448/ $\mu 1(6.000-17.000)$ e

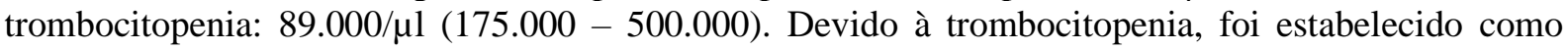
diagnóstico presuntivo a Erliquiose. Foi instituída terapêutica com Doxiciclina $200 \mathrm{mg}$, dois comprimidos por via oral, uma vez ao dia durante 28 dias, para o tratamento da Erliquiose e Omeprazol $40 \mathrm{mg}$, um comprimido por via oral, uma vez ao dia durante 28 dias, como protetor gástrico devido a ação irritante da Doxiciclina. Foi indicada também a realização de uma ultrassonografia abdominal para posterior avaliação, no entanto a mesma não foi autorizada pelo proprietário.

Três meses após o quadro clínico, o animal retornou para realização de ovariohisterectomia, onde o proprietário relatou ter realizado todo o tratamento preconizado anteriormente, apresentando completa 
melhora clínica. Foi realizado o procedimento cirúrgico, com um retorno em 10 dias para a retirada dos pontos, onde o animal apresentava-se hígido.

Trinta e nove dias após a realização da ovariohisterectomia, o proprietário retornou a clínica e relatou que o animal apresentava dificuldade de deambulação em membros pélvicos, dificuldade para se levantar e tremores musculares. No exame físico foi constatada crepitação na articulação coxofemoral. Como exames completares foram solicitados hemograma e radiografia da articulação coxofemoral e coluna. Foi instituído o tratamento com Prednisolona $20 \mathrm{mg}$, dois comprimidos, uma vez ao dia, por três dias até o resultado dos exames, para alívio da dor articular.

Foi realizado hemograma, e o mesmo se apresentava dentro da normalidade, entretanto, na contagem diferencial de leucócitos, foram observados gamontes intraleucocitários de Hepatozoon canis, conforme demonstra a Figura 1, fechando assim o diagnóstico para Hepatozoonose. Devido ao diagnóstico e a necessidade de anestesia para a realização do exame de raio-x coxofemoral, o mesmo foi adiado.

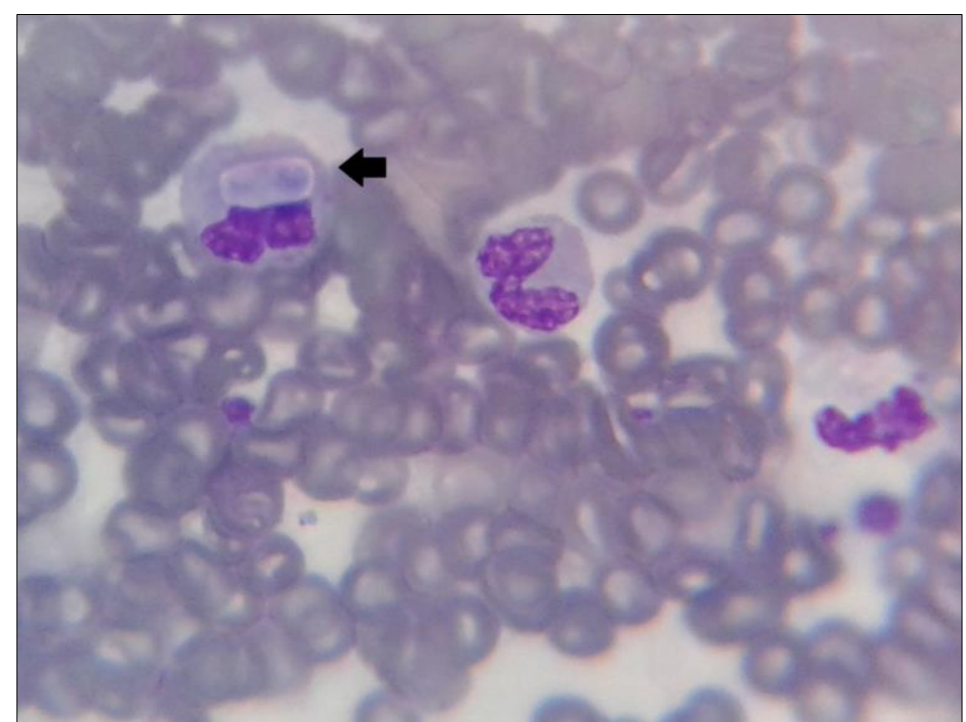

Figura 1. Gamonte de $H$. canis parasitando neutrófilo segmentado. Corado por Giemsa.

Após o diagnóstico foi instituída terapêutica com a aplicação de diprionato de imidocarb na dose de $5 \mathrm{mg} / \mathrm{kg}$, por via intramuscular, em dose única, sendo realizada reaplicação após 14 dias da primeira dose. Já na data da segunda aplicação o proprietário relatou melhora dos tremores musculares e da dificuldade para se levantar.

Vinte e um dias após a segunda dose do diprionato de imidocarb, o animal voltou à clínica apresentando novamente dificuldade de deambulação. $\mathrm{O}$ animal apresentava sobrepeso. No exame físico o animal apresentou parâmetros normais. Foi realizado novo hemograma para descartar a possibilidade de insucesso do tratamento, onde não foram observadas formas gamontes intraleucocitárias. De acordo com os sinais clínicos apresentados pelo animal, foi estabelecendo o diagnóstico presuntivo de displasia coxofemoral.

Foi estabelecido como tratamento o uso de Condromax $\operatorname{Pet}^{\circledR}\left(\right.$ Ourofino $\left.^{\circledR}\right)$, na dose de três tabletes/SID por 30 dias, quando seria realizado um retorno à clínica para nova avaliação. Novamente foi recomendado a realização de raio-x e possível cirurgia para correção da displasia coxofemoral, no entanto o proprietário não retornou mais à clínica. Um ano após a realização do último atendimento, em contato informal com o proprietário, o mesmo relatou que o animal se encontra bem de saúde.

\section{Discussão}

O animal do presente estudo residia na zona rural, próximo a uma área de reserva florestal, e constantemente apresentava-se infestado por carrapatos, o que aumenta a possibilidade de ocorrer a contaminação devido à proximidade com o hospedeiro definitivo (carrapato), conforme descrito na literatura. Bernardino et al. (2014) afirmam como fator predisponente o acesso à rua, além do histórico ou a presença de carrapatos no animal. Silva et al. (2014) em seus resultados relatam uma maior 
incidência da parasitose em animais da zona rural, em relação a zona urbana, atribuindo ao fato de que cães domiciliados no perímetro urbano geralmente apresentam melhor estado físico, devido maior preocupação dos proprietários em relação à saúde de seus animais, além de possuírem uma menor carga de ectoparasitos. Outro aspecto a ser observado é a maior locomoção dos animais residentes na zona rural, promovendo um contato maior com outros animais e com muitas espécies veiculadoras do protozoário.

Por ser o vetor tanto da Hepatozoonose quanto da Erliquiose canina, Rhipicephalus sanguineus pode permitir a exposição simultânea, transmitindo ambos os organismos. Além disso, $H$. canis pode aumentar a susceptibilidade ou promover a manifestação clínica da Erliquiose, devido à imunossupressão (Bustamante \& Varela, 1947; Dantas-Torres et al., 2006).

No caso exposto, o animal foi diagnosticado com E. canis, anteriormente ao diagnóstico de $H$. canis, podendo assim a Erlichiose ter causado um quadro de imunossupressão favorecendo a manifestação do quadro clínico da doença. Ainda há a possibilidade do $H$. canis não ter sido notado na realização do primeiro hemograma, o que não descarta a possibilidade da infecção concomitante das duas doenças. Conforme descrito na literatura, tais doenças podem ocorrer de forma simultânea. Vale ressaltar ainda que há relatos de infecção de um único monócito por um gamonte de H. canis e uma mórula de E. canis, mostrando haver simbiose entre os dois agentes infecciosos (Bustamante \& Varela, 1947; Dantas-Torres et al., 2006). Em investigação de coinfecção com Erlichia sp., Babesia sp., Anaplasma sp., Leishmania spp. e análise de Corpúsculos de Lentz, em cães positivos para $H$. canis, a presença de coinfecção foi observada em 20,83\% dos casos estudados, sendo que, a maior incidência se deu nos casos em que cães possuíam associação de Erlichia sp., sugerindo assim uma maior susceptibilidade a infecções por $H$. canis, quando em associação a Erlichia sp. (Antunes et al., 2015; Bustamante \& Varela, 1947; DantasTorres et al., 2006).

$\mathrm{O}$ animal do presente estudo apresentou sinais de anorexia e apatia, se assemelhando a relatos de dois casos associados a infecções por Erlichia canis, realizado por Mundim et al. (1992) que descrevem estes, como os principais sintomas da hepatozoonose, mostrando a inespecificidade e semelhança dos sinais apresentados nas infecções. Foram relatadas mucosas hiperêmicas, estertores úmidos nos pulmões e taquicardia, sinais estes, que não foram observadas no presente estudo. Deve-se destacar ainda que a infecção mista pode mascarar o quadro apresentado em infecções isoladas, dificultando o diagnóstico quando o animal estiver acometido por mais de um agente.

Deve-se levar em consideração que cães com baixos quadros de parasitemia podem permanecer sem sintomatologia aparente, sugerindo assim, uma maior adaptação da relação parasita-hospedeiro (Spolidorio et al., 2009). No entanto, em quadros onde ocorre o desequilíbrio na relação parasitohospedeiro, o animal infectado geralmente apresenta sinais da infecção (Baneth \& Weigler, 1997).

No presente estudo o animal encaminhado à clínica apresentava dificuldade em permanecer em estação e de deambulação dos membros pélvicos. Segundo a literatura, esses sinais podem ocorrer em animais diagnosticados com $\mathrm{H}$. canis. Além destes sinais, os animais podem apresentar ainda, quadros de anorexia, palidez de mucosas, perda de peso e letargia, podendo em casos mais graves apresentar ainda vômito e diarreia, que pode ou não vir acompanhada de sangue (Bernardino et al., 2014; Chhabra et al., 2013). No entanto, tais sinais não foram observados no animal do presente relato.

No caso apresentado, utilizou-se como protocolo de tratamento o diprionato de imidocarb na dose de $5 \mathrm{mg} / \mathrm{kg}$, por via intramuscular, em dose única, com reaplicação após 14 dias (Birchard \& Sherding, 2008). O tratamento mostrou-se eficaz, sendo que não foram encontrados parasitas nos hemogramas subsequentes e o animal apresentou melhora clínica quanto à presença de tremores musculares.

Sinais clínicos como dor e paresia de membros, foram observados no caso exposto, entretanto não foi possível realizar diagnóstico radiográfico do animal. Deve-se ponderar também que a infecção por $H$. canis pode ter exacerbado o quadro clínico do animal, visto que após o tratamento contra o protozoário, o animal apresentou melhora clínica, com a interrupção dos tremores musculares apresentados anteriormente. Rocha et al. (2008) destacam que a displasia coxofemoral é muito comum em cães de raças de médio e grande porte, como Pastor-Alemão, Rotweiller, Labrador e São Bernardo, se caracterizando por uma enfermidade articular que pode afetar da cabeça e colo do fêmur, até mesmo o acetábulo. 
Em um estudo de Spolidorio et al. (2009) também no estado do Espírito Santo, foi descrito a presença desse parasita em cães nas regiões de Ecoporanga, Nova Venécia e São Mateus. Nesse mesmo trabalho, outras áreas como Colatina, Santa Leopoldina e Vila Valério também foram estudadas, mas os animais se apresentaram negativos para $H$. canis. Vale salientar assim, que a ocorrência deste parasito já foi pesquisada nos municípios vizinhos apresentando casos positivos, mas nunca antes descrita e pesquisada no município de Santa Teresa, podendo assim sugerir que a doença já estava presente na região, ainda não sendo diagnosticada devido um possível sub-diagnóstico, por sua sintomatologia inespecífica.

\section{Conclusão}

Este trabalho registra o primeiro caso de hepatozoonose canina descrito no município de Santa Teresa - Espírito Santo, e levanta a necessidade de se realizarem mais pesquisas da ocorrência do parasita na região. O presente trabalho também serve como um alerta aos médicos veterinários, para que os mesmos tenham uma maior atenção quanto aos sinais clínicos apresentados pelos animais e aos técnicos de laboratório para que façam um exame mais minucioso dos esfregaços sanguíneos, a fim de obter um diagnóstico mais preciso. Diversos autores salientam a possibilidade de estar ocorrendo um subdiagnóstico da parasitose, pois a mesma possui relatos em diversos estados brasileiros, não sendo comumente diagnosticada no atendimento clínico.

\section{Referências bibliográficas}

Antunes, T. R., Valençoela, R. A., Sorgatto, S., Oliveira, B. B., Godoy, K. C. S., \& Souza, A. I. (2015). Aspectos hematológicos e epidemiológicos de cães naturalmente infectados por Hepatozoon sp. no município de Campo Grande, Mato Grosso do Sul, Brasil. Acta Veterinaria Brasilica, 9(3), 234-238.

Baneth, G. (2006). Infectious diseases of the dog and cat. In C. E. Greene (Ed.), Hepatozzon canis Infection (3a ed., p. 698). Elsevier Health Sciences.

Baneth, Gad, \& Weigler, B. (1997). Retrospective case-control study of hepatozoonosis in dogs in Israel. Journal of Veterinary Internal Medicine, 11(6), 365-370. DOI: https://doi.org/10.1111/j.19391676.1997.tb00482.x.

Bentley, C. A. (1905). Preliminary note upon a leucocytozoan of the dog. British Medical Journal, 1(2314), 988. DOI: https://doi.org/10.1136/bmj.1.2314.988.

Bernardino, M. G. S., Meireles, M. V. N., Silva, E. G., Xavier, F. J. R., \& Satake, F. (2014). Caracterização epidemiológica e principais sinais clínicos de cães infectados com hepatozoon canis no município de Areia-PB. Revista de Educação Continuada Em Medicina Veterinária e Zootecnia Do $C R M V-S P, 12(3), 52$.

Birchard, S. J., \& Sherding, R. G. (2008). Manual Saunders: clínica de pequenos animais. In Ed. Roca (Vol. 3).

Bustamante, M. E., \& Varela, G. (1947). Rhipicephalus sanguineus e a epidemiologia da leishmaniose visceral canina no Estado de Pernambuco. Revista Del Instituto de Salubridade y Enfermedades Tropicales, 8(2), 139-141.

Chhabra, S., Uppal, S. K., \& Singla, L. Das. (2013). Retrospective study of clinical and hematological aspects associated with dogs naturally infected by Hepatozoon canis in Ludhiana, Punjab, India. Asian Pacific Journal of Tropical Biomedicine, 3(6), 483-486. DOI: https://doi.org/10.1016/S22211691(13)60100-8.

Dantas-Torres, F., Figueredo, L. A., \& Brandão-Filho, S. P. (2006). Rhipicephalus sanguineus (Acari: Ixodidae), the brown dog tick, parasitizing humans in Brazil. Revista Da Sociedade Brasileira de Medicina Tropical, 39(1), 64-67. DOI: https://doi.org/10.1590/s0037-86822006000100012

Gonen, L., Strauss-Ayali, D., Shkap, V., Vincent-Johnson, N., Macintire, D. K., \& Baneth, G. (2004). An enzyme-linked immunosorbent assay for antibodies to Hepatozoon canis. Veterinary Parasitology, 122(2), 131-139. DOI: https://doi.org/10.1016/j.vetpar.2004.03.021.

Greene, C. E., Samperio, J. O., \& Gómez, J. P. (1993). Enfermedades infecciosas: Perros y gatos. Editora Interamericana.

Hartmann, K. (2006). Infectious diseases of the dog and cat (3ed ed., Vol. 1). Elsevier Health Sciences.

Massard, C. A. (1979). Hepatozoon canis (James, 1905)(Adeleida: Hepatozoidae) de cães do Brasil, com 
uma revisão do gênero em membros da ordem carnívora. Universidade Federal do Rio de Janeiro.

Mundim, A. V., Jacomini, J. O., Mundim, M. J. S., \& Araújo, S. F. (1992). Hepatozoon canis (James, 1905) em cães de Uberlândia, Minas Gerais. Relato de dois casos. Brazilian Journal of Veterinary Research and Animal Science, 29, 359-361. DOI: https://doi.org/10.11606/issn.16784456.bjvras.1992.52001.

Mundim, A. V., Mundim, V. J. S., \& Barbosa, F. C. (2002). Hepatozoonosis canina. Veterinária Noticias, 8(2), 141-151.

O’Dwyer, L. H., Massard, C. L., \& Souza, J. C. P. (2001). Hepatozoon canis infection associated with dog ticks of rural areas of Rio de Janeiro State, Brazil. Veterinary Parasitology, 94(3), 143-150. DOI: https://doi.org/10.1016/s0304-4017(00)00378-2

O'Dwyer, L. H., Saito, M. E., Hasegawa, M. Y., \& Kohayagawa, A. (2004). Tissue stages of Hepatozoon canis in naturally infected dogs from Sao Paulo State, Brazil. Parasitology Research, 94(3), 240-242. DOI: https://doi.org/10.1007/s00436-004-1190-9

Paludo, G. R., Dell'Porto, A., Trindade, A. R. de C., McManus, C., \& Friedman, H. (2003). Hepatozoon spp.: report of some cases in dogs in Brasilia, Brazil. Veterinary Parasitology, 118(3), 243-248. DOI: https://doi.org/10.1016/j.vetpar.2003.10.009

Ramos, C. A. N., Babo-Terra, V. J., Pedroso, T. C., Souza Filho, A. F., Araújo, F. R., \& Cleveland, H. P. K. (2015). Molecular identification of Hepatozoon canis in dogs from campo grande, mato grosso do sul, Brazil. Revista Brasileira de Parasitologia Veterinária, 24(2), 247-250. DOI: https://doi.org/10.1590/s1984-29612015019.

Rocha, F. P. C., Silva, D., Benedette, M. F., Santos, D. A. N., Costa, E. A. A., \& Dias, L. G. G. G. (2008). Displasia coxofemoral em cães. Revista Científica Eletrônica de Medicina Veterinária, 4(11), 1-7.

Silva, M. C. A., Mundim, A. V., Mendonça, G. A., Mundim, M. J. S., \& Guimarães, E. C. (2014). Hemoparasitos em cães domésticos naturalmente infectados, provenientes das zonas urbana e rural do município de Abadia dos Dourados, Minas Gerais, Brasil. Bioscience Journal, 30(5), 892-900.

Spolidorio, M. G., Labruna, M. B., Zago, A. M., Donatele, D. M., Caliari, K. M., \& Yoshinari, N. H. (2009). Hepatozoon canis infecting dogs in the State of Espírito Santo, southeastern Brazil. Veterinary Parasitology, 163(4), 357-361. DOI: https://doi.org/10.1016/j.vetpar.2009.05.002.

Recebido: 10 de abril, 2020

Aprovado: 30 de maio, 2020.

Disponível online: 17 de agosto, 2020

Licenciamento: Este artigo é publicado na modalidade Acesso Aberto sob a licença Creative Commons Atribuição 4.0 (CC-BY 4.0), a qual permite uso irrestrito, distribuição, reprodução em qualquer meio, desde que o autor e a fonte sejam devidamente creditados. 